\title{
Rheumatoid arthritis in an urban South African Negro population
}

\author{
L. SOLOMON, G. ROBIN,* AND H. A. VALKENBURG $\dagger$ \\ From the Epidemiological Research Unit, Department of Orthopaedic Surgery, \\ University of the Witwatersrand, Johannesburg, South Africa
}

\begin{abstract}
Solomon, L., Robin, G., and Valkenburg, H. A. (1975). Annals of the Rheumatic Diseases, 34, 128. Rheumatoid arthritis in an urban South African Negro population. (1) An epidemiological study of an urban South African Negro community has been carried out in Johannesburg. Altogether 964 respondents were examined and in each case radiographs of the hands and feet were obtained. Rheumatoid factor tests were carried out on 404 serum samples. (2) Rheumatoid arthritis (RA) was graded 'definite' or 'probable' on the basis of a modification of the Rome criteria (Kellgren, Jeffrey, and Ball, 1963a). (3) In marked contrast to the findings in rural Africans, the prevalence of RA in this community was similar to that in Caucasian populations. Five respondents (all elderly women) had 'definite' RA, giving a prevalence of $1 . \% 4$ of the females and $0.9 \%$ of the total population sample over 15 years old. The prevalence of 'definite' and 'probable' RA combined was $2.6 \%$ for males, $3.7 \%$ for females, and $3.3 \%$ for all individuals over 15 years old. Prevalence increased with age, reaching a maximum in the 65- to 74-year cohort. (4) The form and severity of the clinical and radiological features were unlike the mild manifestations seen in rural African peoples and closely resembled the usual clinical picture of rheumatoid disease. (5) The latex fixation test was positive in $12.1 \%$ of the sera tested, which is similar to the high titres found in other African populations. No obvious cause for this phenomenon was found. (6) Several reasons for the marked difference in prevalence of RA between this urban African population and a rural African population are considered. Marked intraracial differences such as this point to the importance of sociological and environmental factors in the pathogenesis of rheumatoid arthritis.
\end{abstract}

Though rheumatoid arthritis (RA) has been described in several different African populations (Hall, 1966; Gelfand, 1969; Kanyerezi, 1969; Greenwood, 1969; Kanyerezi, Baddeley, and Kisumba, 1970; Anderson, 1971), it is still thought to be rare in these peoples. This belief has been strengthened by the findings in two recent prevalence studies. A survey in Western Nigeria and Liberia showed that 'definite' and 'probable' rheumatoid arthritis combined occurred in $0.8 \%, 1.6 \%$, and $2.8 \%$ of the people in three different villages (Muller, 1970). A similar epidemiological study was carried out in a Tswana village in South Africa, 3000 miles south of Nigeria, and is described in an accompanying paper (Beighton, Solomon, and Valkenburg, 1975). A prevalence of $0.12 \%$ for 'definite' RA and $0.87 \%$ for 'definite' and 'probable' RA combined was found. This is much lower than the reported figures for European and American populations (Cobb, Warren, Merchant, and Thompson, 1957; Lawrence, 1961 ; Laine, 1962; Mikkelson, Dodge, Duff, Epstein, and Napier, 1963; Bunim, Burch, and O'Brien, 1964). However, the above studies relate to rural Africans living in a tribal or semitribal cultural environment and cannot be re- N garded as representative of all African Negroes.

A comparative survey has now been conducted in an urban African community living in the metropolitan area of Johannesburg.

\section{The urban African-historical background}

With the opening of the goldfields on the Witwatersrand in 1886, thousands of Africans were drawn to the area by the prospect of work. Those employed on the mines were housed by their employers and to this day the mine-labourers live as a separate community iso- 
lated from the urban society of Johannesburg. At the turn of the century they constituted about half of the city's African population of over 100000 , but with the passing of each year the proportion has diminished as the total number of Africans has grown.

By 1918 the need for planned accommodation of those not housed on the mines had become pressing and within 3 years the first small African township was established. It was hopelessly inadequate and for every municipal house six illegal shanties sprang up. As late as 1927 only 15000 of the estimated 100000 Africans (excluding those on the mines) were in municipal housing.

During the next 10 years the African population of Johannesburg more than doubled itself and, under the pressure of this expansion, the local Council started planning the development of a large new township on the south-western outskirts of the city. This was Orlando, which was settled in the early 1930s.

Another major population increase followed the rapid industrial expansion of the war years and by 1946 there were almost a half-million Africans living in and around Johannesburg. Squatter-camps appeared on vacant public land and the area adjacent to Orlando turned into one vast slum. More townships were proclaimed and in the late 1950 s a massive rehousing scheme was begun. On the rubble of the old shanty-towns there rose the sprawling complex of African townships that today covers the southwestern slopes of the Johannesburg metropolitan area.

\section{Demography}

The South-Western Townships (known collectively as Soweto) have grown to 24 in number, and together they constitute the largest urban complex in Southern Africa; 586000 of Johannesburg's estimated 3/4 million Africans live here. There are 141 schools and 47 day nurseries in Soweto. Municipal health services include six general clinics, six family health centres, and six tuberculosis clinics. They are linked to the 2000 -bed teaching hospital at Baragwanath. The area as a whole is governed by a local Bantu Council of 58 members but is still under the overall control of the Johannesburg City Council.

In the early years the people of Soweto were regarded as migratory workers with no permanent roots in the city. Today, even though they retain many of their tribal customs, they are true city dwellers, their lives alternating between the commercial centre of Johannesburg and the domestic clusters of the townships.

The survey described here was carried out in Orlando East, the oldest and second most populous of these suburbs. Many of its 7000-odd families have been living there since it was established in 1932 . Over $80 \%$ of its people were either born in Johannesburg or have lived here for at least 20 years.

In June, 1972, there were 31753 residents in Orlando East; the population structure is shown in the Figure. Being the most settled of the African communities around

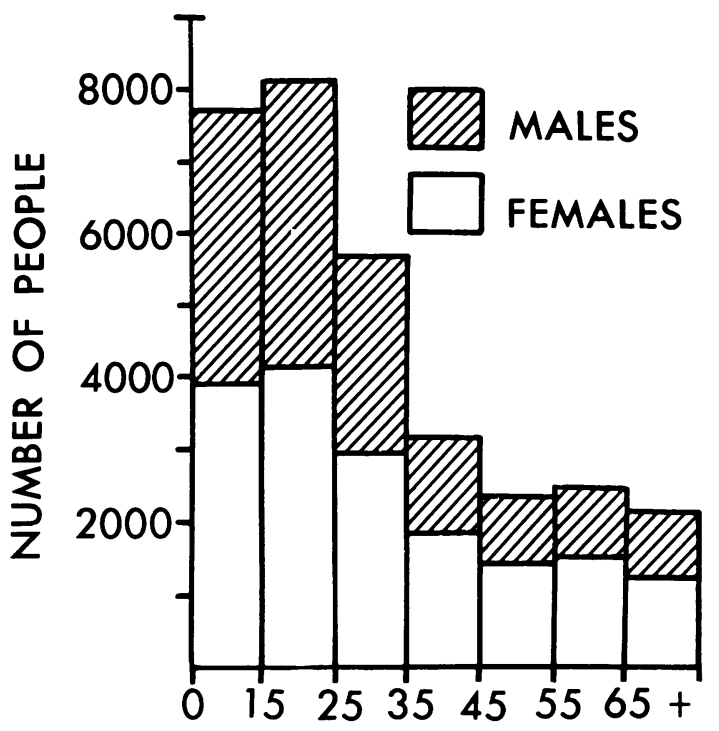

\section{AGE IN YEARS}

FIGURE Population structure of Orlando East in June, 1972. (Data supplied by Johannesburg Native Affairs Department)

Johannesburg, $7 \cdot 0 \%$ are over 64 years old, compared with the average of $3.0 \%$ for the whole of Soweto.

METHOD OF SURVEY

On a street map of Orlando East 15 blocks of houses were randomly selected. A complete census of these areas was carried out; at the same time the census-taker explained the purpose of the survey. Respondents were collected by bus and transported to a nearby Municipal Clinic; here they were examined, radiographs of the hands and feet were obtained in every case and blood samples were taken from those over 18 years. In addition, everyone over 35 years, excepting pregnant women, was taken to Baragwanath Hospital for radiography of the pelvis and spine.

People of non-Negro stock-including those of mixed Caucasian or Khoi-San and Negro parentage-were excluded from the survey, but no further selection by ethnic group was made. This left a total of 946 respondents, representing a completion rate, according to the original census, of $75 \%$. The age and sex distribution is shown in Table I.

The survey was completed within a period of 8 weeks and took place one year after the Tswana survey reported in an accompanying paper (Beighton and others, 1975).

\section{Results}

Rheumatoid arthritis was diagnosed according to the modified Rome criteria (Kellgren and others, 1963a) used in the rural African survey (Beighton and others, 1975). 
Table I Age and sex distribution of the 946 respondents

\begin{tabular}{|c|c|c|c|c|c|c|}
\hline \multirow{2}{*}{$\begin{array}{l}\text { Age group } \\
\text { (years) }\end{array}$} & \multicolumn{2}{|c|}{ Males } & \multicolumn{2}{|c|}{ Females } & \multicolumn{2}{|c|}{ Total } \\
\hline & No. & $\%$ & No. & $\%$ & No. & $\%$ \\
\hline $0-14$ & 195 & $49 \cdot 7$ & 200 & $36 \cdot 1$ & 395 & $41 \cdot 8$ \\
\hline $15-24$ & 70 & 17.9 & 109 & $19 \cdot 7$ & 179 & 18.9 \\
\hline $25-34$ & 34 & $8 \cdot 7$ & 65 & $11 \cdot 7$ & 99 & $10 \cdot 5$ \\
\hline $35-44$ & 25 & $6 \cdot 4$ & 40 & $7 \cdot 2$ & 65 & 6.9 \\
\hline $45-54$ & 16 & $4 \cdot 1$ & 36 & 6.5 & 52 & $5 \cdot 5$ \\
\hline $55-64$ & 23 & 5.9 & 44 & $8 \cdot 0$ & 67 & $7 \cdot 1$ \\
\hline $65-74$ & 21 & $5 \cdot 4$ & 43 & $7 \cdot 8$ & 64 & $6 \cdot 8$ \\
\hline 75 and over & 8 & $2 \cdot 0$ & 17 & $3 \cdot 1$ & 25 & $2 \cdot 7$ \\
\hline Total & 392 & 100 & 554 & 100 & 946 & 100 \\
\hline Percentage & $41 \cdot 4$ & & $58 \cdot 6$ & & 100 & \\
\hline
\end{tabular}

\section{CLINICAL ASSESSMENT}

Twenty-four respondents, 7 men and 17 women, had clinical polyarthritis (Table II). Two had long-standing rheumatoid disease with erosive arthritis and had required hospitalization on several occasions in the past. Another nine presented the clinical appearances of an inflammatory polyarthritis with involvement of the wrists, metacarpophalangeal and interphalangeal joints, but without the classical deformities of rheumatoid disease. Seven of this group had positive rheumatoid factor tests and six had radiographic changes of grade 2 or 3 erosive arthritis.

The remaining thirteen people were assessed as having polyarthritis in the sense that multiple joints were simultaneously painful, tender on palpation, and possibly swollen, but the distribution was asymmetrical and haphazard. Only one of these individuals had a positive latex fixation test (LFT), but no less than five had features of erosive arthritis in the routine radiographs of the hands or feet.

\section{RADIOGRAPHIC ASSESSMENT}

The radiographs were assessed according to the Atlas of Standard Radiographs of Arthritis (Kellgren, Jeffrey, and Ball, 1963b). All the plates were initially examined by one investigator (L.S.) and were checked by two independent observers. A diagnosis of erosive arthritis was accepted only when there was agreement between the three readings.

Four respondents, all women, had grade 3 or 4 arthritis of the small joints of the wrists, hands, or feet; another 21 had features of grade 2 arthritis, producing a total of 25 individuals with radiographic evidence of erosive joint changes (Table II). Thirteen of these had clinical polyarthritis and nine had positive rheumatoid factor tests.

\section{SEROLOGICAL EXAMINATION}

The LFT and human erythrocyte agglutination test (HEAT) were used to determine the presence of rheumatoid serum factors. The tests were carried out in the same laboratory (H.V.) as those employed in the rural survey reported elsewhere (Beighton and others, 1975). Titres of $1: 640$ for the LFT and $1: 32$ for the HEAT were regarded as positive. The LFT was also assessed after inactivation of serum inhibitor by incubating at $56^{\circ} \mathrm{C}$.

Altogether 404 serum samples from those over 15 years of age were examined, 135 from males and 269 from females. The results are shown in Tables III and IV. A positive LFT was obtained in 49 respondents- 17 men and 32 women. This represents $12.6 \%$ of the men and $11.9 \%$ of the women tested, and gives an overall prevalence of $12 \cdot 1 \%$. In both sexes the percentage of positive results increased with age, reaching

Table II Age and sex specific prevalence of clinical polyarthritis and erosive arthritis of hands and feet (551 respondents 15 years old and over)

\begin{tabular}{|c|c|c|c|c|c|c|c|c|c|c|c|c|c|c|c|c|c|c|}
\hline \multirow{2}{*}{$\begin{array}{l}\text { Age group (years) } \\
\text { Sex }\end{array}$} & \multicolumn{2}{|c|}{$15-24$} & \multicolumn{2}{|c|}{$25-34$} & \multicolumn{2}{|c|}{$35-44$} & \multicolumn{2}{|c|}{$45-54$} & \multicolumn{2}{|c|}{$55-64$} & \multicolumn{2}{|c|}{$65-74$} & \multicolumn{2}{|c|}{$75+$} & \multicolumn{2}{|c|}{$\begin{array}{l}15 \text { and } \\
\text { over }\end{array}$} & \multicolumn{2}{|c|}{$\begin{array}{l}\text { Total Male } \\
\text { and Female }\end{array}$} \\
\hline & $M$ & $F$ & $M$ & $F$ & $M$ & $F$ & $M$ & $F$ & $M$ & $F$ & $M$ & $F$ & $M$ & $F$ & $M$ & $F$ & No. & $\%$ \\
\hline Sample & 70 & 109 & 34 & 65 & 25 & 40 & 16 & 36 & 23 & 44 & 21 & 43 & 8 & 17 & 197 & 354 & 551 & \\
\hline Obvious RA & & & & & & & & & & & & 1 & & 1 & & 2 & 2 & $0 \cdot 36$ \\
\hline Symmetrical polyarthritis & & & & & & & & 2 & & 3 & & 2 & 1 & 1 & 1 & 8 & 9 & $1 \cdot 6$ \\
\hline Asymmetrical polyarthritis & & & & & & 1 & 1 & & 1 & 2 & 4 & 4 & & & 6 & 7 & 13 & $2 \cdot 4$ \\
\hline Total with polyarthritis & & & & & & 1 & 1 & 2 & 1 & 5 & 4 & 7 & 1 & 2 & 7 & 17 & 24 & $4 \cdot 4$ \\
\hline Erosive arthritis grade $3 / 4$ & & & & & & & & & & & & 3 & & 1 & & 4 & 4 & 0.7 \\
\hline Erosive arthritis grade 2 & & & & & 2 & & 3 & 1 & & 4 & 3 & 3 & 3 & 2 & 11 & 10 & 21 & $3 \cdot 8$ \\
\hline Total with erosive arthritis & & & & & & & & & & & & & & & 11 & 14 & 25 & $4 \cdot 5$ \\
\hline
\end{tabular}




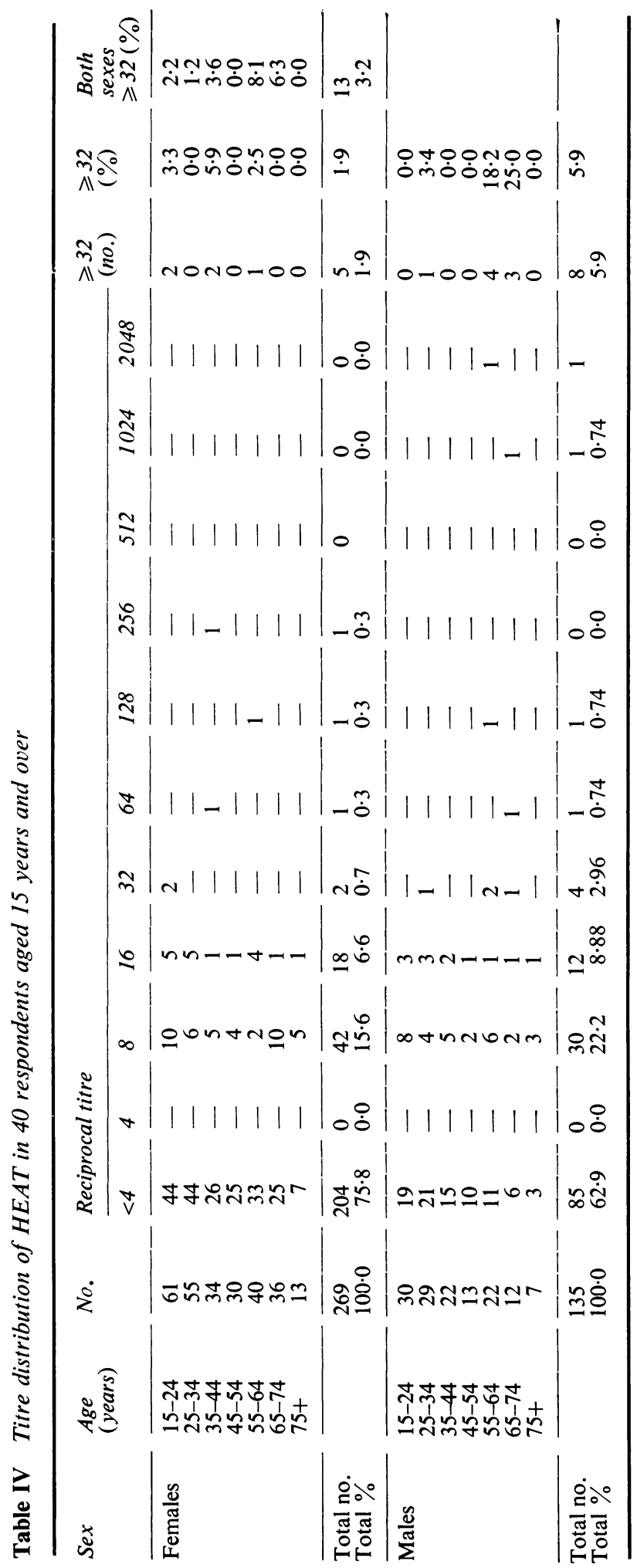


a maximum of $22.9 \%$ in the $65-$ to 74 -year cohort. Incubation of the serum at $56^{\circ} \mathrm{C}$ to inactivate inhibitor had very little effect on the results.

The HEAT was positive in 13 individuals- 8 males and 5 females. This represents $5.9 \%$ of the men and $1.9 \%$ of the women, giving an overall prevalence of $3.2 \%$. The increase in percentage of positive tests with age was not as striking as with the LFT, but the highest titres were again recorded in the 6 th and 7 th decades.

\section{EVALUATION OF COMBINED CRITERIA}

In order to allow comparison of this survey with the rural African survey, the final assessment of arthritis was based on the same criteria as before. Those cases fulfilling the three criteria of symmetrical polyarthritis including the joints of the hands or feet, radiographic evidence of erosive arthritis in the hands or feet, and a positive LFT or HEAT, were classified as 'definite' RA; those fulfilling two of the three criteria were classified as 'probable' RA.

Five respondents fulfilled the criteria for diagnosis of 'definite' RA. All were women over the age of 60 years. This is $1.4 \%$ of the females over 15 years and represents an overall prevalence of $0.9 \%$ of the total sample of 551 individuals over 15 years.

Another 13 respondents, 5 men and 8 women, had 'probable' RA. The combined prevalence for 'definite' and 'probable' RA was therefore $2.6 \%$ for males, $3 \cdot 7 \%$ for females, and $3 \cdot 3 \%$ for all individuals over 15 years (Table V).

The racial distribution of those with 'definite' and 'probable' RA is shown in Table VI. The differences are not statistically significant.

\section{Discussion}

Contrary to the expectations engendered by previous studies in African populations, the prevalence of RA in this urban African community was strikingly similar to that in other industrialized countries throughout the world $; 3.3 \%$ of those over 15 years old had 'definite' or 'probable' RA, compared with $0.87 \%$ of the rural African population described in an accompanying paper. The difference is highly significant.* Moreover, the form of the inflammatory polyarthritis encountered resembled that of clinical rheumatoid disease much more closely than did the very mild and even dubious manifestations reported in other African studies. Indeed, apart from the five respondents classified as having 'definite' RA, another six had clinical features suggestive of rheumatoid disease, including chronic synovitis of the wrists and metacarpophalangeal joints, but without the other criteria to permit a diagnosis of 'definite' RA; two of these were seropositive and were thus included in the category of 'probable' RA, but the remaining four had neither positive rheumatoid factor tests nor radiographic signs of erosive arthritis and were therefore not reflected at all in the final calculation of prevalence. In addition, one respondent (a 71-yearold woman) had undoubted clinical and radiological features of rheumatoid arthritis but being seronegative she was classified as 'probable' rather than 'definite' RA. These observations strengthen the assertion that the rheumatoid type of inflammatory poly-

* Rural group: RA in 7 out of 801 .
Urban group: RA in 18 out of 551 .
$\lambda^{2} 1$ df with Yates's correction $=8.44 ; P<0.01$.

Table $\mathbf{V}$ Age and sex specific prevalence of combined 'definite' and 'probable' rheumatoid arthritis (551 respondents 15 years and over)

\begin{tabular}{|c|c|c|c|c|c|c|c|c|c|c|c|c|c|c|c|c|c|}
\hline \multirow{2}{*}{$\begin{array}{l}\text { Age group (years) } \\
\text { Sex }\end{array}$} & \multicolumn{2}{|c|}{$15-24$} & \multicolumn{2}{|c|}{$25-34$} & \multicolumn{2}{|c|}{$35-44$} & \multicolumn{2}{|c|}{$45-54$} & \multicolumn{2}{|c|}{$55-64$} & \multicolumn{2}{|c|}{$65-74$} & \multicolumn{2}{|c|}{$75+$} & \multicolumn{2}{|c|}{15 and over } & \multirow[t]{2}{*}{ Total } \\
\hline & $M$ & $F$ & $M$ & $F$ & $M I$ & $F$ & $M$ & $F$ & $M$ & $F$ & $M$ & $F$ & $M$ & $F$ & $M$ & $F$ & \\
\hline Sample & 70 & 109 & 34 & 65 & 25 & 40 & $\overline{16}$ & 36 & 23 & 44 & 21 & 43 & 8 & 17 & 197 & 354 & 551 \\
\hline Rheumatoid arthritis & 0 & 0 & 0 & 0 & 2 & 0 & 1 & 1 & 0 & 4 & 2 & 6 & 0 & 2 & 5 & 13 & 18 \\
\hline Percentage & 0 & 0 & 0 & 0 & $8 \cdot 0$ & 0 & $6 \cdot 3$ & $2 \cdot 8$ & 0 & $9 \cdot 1$ & $9 \cdot 5$ & & 0 & $11 \cdot 8$ & $2 \cdot 6$ & $3 \cdot 7$ & $3 \cdot 3$ \\
\hline Total percentage & & 0 & & 0 & & $3 \cdot 1$ & & $3 \cdot 8$ & & $6 \cdot 0$ & & $2 \cdot 5$ & & 8 & & $3 \cdot 3$ & \\
\hline
\end{tabular}

Table VI Race specific prevalence of combined 'definite' and 'probable' rheumatoid arthritis in 551 respondents of 15 years and over. (The closely related Tswana and Sotho are considered as a single group)

\begin{tabular}{|c|c|c|c|c|c|}
\hline Racial group & Tswana and Sotho & Zulu & Xosa & Other & Total \\
\hline No. in survey & 250 & 147 & 83 & 71 & 551 \\
\hline Rheumatoid arthritis & 6 & 3 & 4 & 5 & 18 \\
\hline Percentage & $2 \cdot 4$ & $2 \cdot 0$ & $4 \cdot 8$ & 6.9 & $3 \cdot 3$ \\
\hline
\end{tabular}


arthritis is not at all uncommon in the Johannesburg African and the prevalence figures presented here are not based on equivocal manifestations of disease.

Equally striking was the frequency of erosive arthritis of the hands or feet, which was diagnosed radiologically in 25 respondents, $4.5 \%$ of those over 15 years and $9.2 \%$ of those over 35 . This is considerably higher than the prevalence in the rural Africans and approaches that in the Jamaican population studies by Lawrence, Bremner, Ball, and Burch (1966). Among the females there was excellent correlation with clinical and serological criteria, eleven out of fourteen having either polyarthritis or positive rheumatoid factor tests or both. Four of the eleven males with erosive arthritis had one or both of the other features.

The type of erosive arthritis also differed from that in the rural survey. Four respondents had grade 3 or 4 arthritis, three of these showing the changes of advanced rheumatoid disease. On the other hand, the well demarcated, sclerotic erosions seen in the Phokeng population were not encountered at all.

As in other African populations, the LFT for rheumatoid factor was positive in a high percentage of cases, $12.1 \%$ of those over 15 years. Though it is tempting to conclude that this reflects some genetic characteristic which is shared by both urban and rural Africans, it is far more likely that both population groups have been exposed to a common environmental factor which affects immunoglobulin levels. Pulmonary tuberculosis, for example, is well known to be associated with a positive LFT in a significant percentage of cases (Singer, Plotz, Peralta, and Lyons, 1962); as in Phokeng, all forms of tuberculosis are relatively common in Soweto, the annual rate having remained fairly constant around 5/1000 over the last 20 years.

\section{AGE AND SEX (TABLE V)}

There was an increase in frequency of all degrees of rheumatoid arthritis with age, up to a maximum of $12.5 \%$ in the 65 - to 74-year cohort. Females outnumbered males by approximately $1 \cdot 5: 1$. This is similar to the age and sex distribution of RA in Caucasian populations (Cobb, 1971), but differs from that in the rural Africans of Phokeng where the women appear to be even less frequently affected than the men.

It is worth noting that all those with 'definite' RA were women, and all but one were over 70 years. The people studied may be considered to be the oldest urban African population in Southern Africa; surveys of African populations that are less settled in the city environment or have a less favourable general age and sex distribution may not show the high prevalence recorded here.

Cobb (1971) has remarked on the fact that it is chiefly in the category of 'definite' RA that there is any marked excess of females over males. This is the case, too, in the urban African; all those with 'definite' RA were women while in those with 'probable' RA the female:male ratio was 8:5.

\section{RACE AND CULTURE}

The rural Africans reported in the accompanying paper (Beighton and others, 1975) all belonged to a single tribe, the Tswana. Strictly speaking, therefore, a comparative survey of urban Africans should be confined to the same tribal group. For both social and logistic reasons this was impossible. It is highly unlikely, however, that it affected the findings in any significant manner. The genetic distances between the four major groups of Bantu-speaking South African Negroes-Tswana, Sotho, Zulu and Xosa - are very small (Shapiro, 1951a, b; Jenkins, Harpending, and Nurse, 1973), and these peoples may, for practical purposes, be regarded as a homogeneous population. In the sample studied the prevalence of RA showed no statistically significant variation among the different racial subgroups (Table VI).

On the evidence presented here one must conclude that the marked differences in the occurrence of RA in the Africans of Phokeng and those of Johannesburg are due not to racial or genetic, but to social or environmental factors.

What those factors are is open to conjecture. For the African Negro over the past half-century, urbanization has meant much more than a geographic translocation. It has brought a profound cultural change from a simple, agrarian existence to a highly competitive, commercially orientated way of life. Overcrowding, different dietary habits, prostitution, exposure to new types of infection, a high rate of venereal disease, alterations in physical activity, a time-dominated routine, and a marked increase in psychological stress are all part of the change, and each has at one time or another been suspected of contributing to the pathogenesis of rheumatic disorders.

A more precise correlation between any of these factors and disease expression must await further investigation.

The data on tuberculosis rates were supplied by the Medical Officer of Health for Johannesburg. We are grateful to the Johannesburg Native Affairs Department for their co-operation in this investigation. The project was supported jointly by the Orthopaedic Chair Trust Fund and the Carl and Emily Fuchs Foundation. 


\section{References}

ANDERSON, I. F. (1971) S. Afr. med. J., 45, 1032 (Rheumatoid arthritis in the Bantu)

Beighton, P., Solomon, L., AND Valkenburg, H. A. (1975) Ann. rheum. Dis., 34, 136 (Rheumatoid arthritis in a rural South African Negro population)

Bunim, J. J., Burch, T. A., AND O'BRIEN, W. M. (1964) Bull. rheum. Dis., 15, 349 (Influence of genetic and environmental factors on the occurrence of rheumatoid arthritis and rheumatoid factor in American Indians)

Совв, S. (1971) In 'The Frequency of the Rheumatic Diseases'. Harvard University Press, Cambridge, Mass.

- WARren, J. E., Merchant, W. R., ANd Thompson, D. J. (1957)J. chron. Dis., 5, 636 (An estimate of the prevalence of rheumatoid arthritis)

Gelfand, M. (1969) Cent. Afr. J. Med., 15, 131 ('Medical' arthritis in African practice)

Greenwood, B. M. (1969) Ann. rheum. Dis., 28, 488 (Polyarthritis in Western Nigeria. I. Rheumatoid arthritis)

HALl, L. (1966) E. Afr. med. J., 43, 161 (Polyarthritis in Kenya)

JenKins, T., HARPENDING, H., AND NuRse, G. T. (1973) 'Genetic distances among certain South African populations', in 'Proceedings of the 9th International Congress of Anthropological and Ethnological Sciences', Chicago, August 1973.

KANYEREZI, B. R. (1969) E. Afr. med. J., 46, 71 (Rheumatoid arthritis in Uganda)

-, Baddeley, H., AND Kisumba, D. (1970) Ann. rheum. Dis., 29, 617 (Rheumatoid arthritis in Ugandan Africans)

Kellgren, J. H., JefFrey, M. R., And Ball, J. (1963a) 'Proposed diagnostic criteria for use in population studies', in 'The Epidemiology of Chronic Rheumatism. Vol. 1, p. 324. Blackwell, Oxford.

— _ _ - (1963b) 'The Epidemiology of Chronic Rheumatism. Vol. 2. Atlas of Standard Radiographs of Arthritis'. Blackwell, Oxford.

LAINE, V. A. I. (1962) Acta rheum. scand., 8, 81 (Rheumatic complaints in an urban population in Finland)

LaWrence, J. S. (1961) Ann. rheum. Dis., 20, 11 (Prevalence of rheumatoid arthritis)

- Bremner, J. M., BAll, J., AND BurCh, T. A. (1966) Ibid., 25, 59 (Rheumatoid arthritis in a subtropical population)

Mikkelson, W. M., Dodge, H. J., Duff, I. F., Epstein, F. H., AND Napier, J. A. (1963) ‘Clinical and serological estimates of the prevalence of rheumatoid arthritis in the population of Tecumseh, Michigan, 1959-60', in 'Epidemiology of Chronic Rheumatism', p. 239. Blackwell, Oxford

Muller, A. S. (1970) Population Studies on the Prevalence of Rheumatic Diseases in Liberia and Nigeria. MD Thesis. University of Leiden.

ShAPIRo, M. (1951a) S. Afr. med. J., 25, 165, 187. (The ABO, MN, P and Rh blood group systems in the South African Bantu)

- (1951b) Ibid., 25, 406 (Further evidence of homogeneity of blood group distribution in the South African Bantu)

Singer, J. M., Plotz, C. M., Peralta, F. M., and Lyons, H. C. (1962) Ann. intern. Med., 56, 545 (The presence of anti-gamma globulin factors in sera of patients with active pulmonary tuberculosis). 